\title{
An Analysis of the Financing Methods of Chinese Listed Companies-Taking TaiChi Group as an Example
}

\author{
Xianping Yuan, Xiaomei Ma* \\ School of Xi'an University of Science and Technology, Xi'an, China \\ Email: *13209852899@163.com
}

How to cite this paper: Yuan, X.P. and Ma, X.M. (2018) An Analysis of the Financing Methods of Chinese Listed Companies-Taking TaiChi Group as an Example. Open Access Library Journal, 5: e4358.

https://doi.org/10.4236/oalib.1104358

Received: January 22, 2018

Accepted: February 25, 2018

Published: February 28, 2018

Copyright $\odot 2018$ by authors and Open Access Library Inc.

This work is licensed under the Creative Commons Attribution International License (CC BY 4.0).

http://creativecommons.org/licenses/by/4.0/

\begin{abstract}
Raising funds is the starting point of the enterprise's production and management activities. The financing of enterprises involves many problems, among which the choice of financing means is a very important part. Taking TaiChi Group as an example, this paper discusses the financing characteristics of Chinese listed companies and analyzes the existing problems. Finally, it puts forward countermeasures and suggestions for the unreasonable financing preference of Chinese enterprises.
\end{abstract}

\section{Subject Areas}

Business Theories, Consumer Behavior, Marketing Theory and Applications

\section{Keywords}

Listed Company, Financing Modes, Taiji Group

\section{Introduction}

The enterprises as the cell of the national economy, to the whole social economy development and progress have an irreplaceable role. Business is simple. The prerequisite for reproducing and expanding reproduction is capital, and funds are like. Money is like the blood of an enterprise, and financing is the main function of the "hematopoiesis" financial management and the prerequisite for the enterprise to maintain the normal operation. Whether a business capital raising decision is correct or not is directly related to whether the enterprise can continue to survive and develop and the economic benefit is good or bad. The correct choice will make the enterprise reasonably avoid the wind in the financing 
decision. It will reduce the cost and raise the efficiency of financing. Enterprises are in different stages of development. There are often differences in the environment and business risk in and outside the market. So enterprises should analyze their own development phase of the money. The choice of financing methods is studied, and the prevention of financing is due to financing. The choice of the way of raising money caused by preference is not reasonable, which leads to the capital. The unbalance of the structure causes the financial crisis. Therefore, to discuss the fundraising side of the enterprise, it is of great significance to the cost and value of the enterprise. TaiChi group gained profits and profits through selling assets in the past two years; although it has brought capital income to enterprises in a short time, the financial situation is not optimistic. The factors causing the TaiChi group status are a lot; in addition to the main business pressure, ways of financing for the development of enterprises will also bring a certain impact; therefore, Taiji Group is taken as an example to explore the characteristics and problems of the financing of Chinese listed companies.

\section{Literature Review and Theoretical Review}

\subsection{Literature Review}

Foreign financing channels, financing methods and financing characteristics. The research of structure started earlier, and its research on financing theory has gone through a gradual and mature process. Ross (1972) believes that when enterprises have a better prospect for development, they generally choose to raise funds in debt. And when the future of the enterprise is bleak, it chooses stock raising [1]. Smith and watts (1992) believe that investment opportunities have been raised for the company. The investment policy has a strong explanatory power [2]. Simon (2002) thought insufficient supplementary operating funds and poor capital structure of the enterprise. It is an important factor in the financing of an enterprise, and it is directly determined. It is an important factor in the financing of an enterprise, and it is directly determined the financing mode of the enterprise [3].

The research of domestic enterprise financing has developed rapidly since the reform and opening up in 1978. A large number of financial experts and scholars have put forward a lot of views on the financing of enterprises. The research on the financing channels and ways of financing is mainly focused on the influencing factors, the selection strategy and the direction of development [4]. The purpose of enterprise financing is to produce the normal production of the enterprise itself the operation and development can be summarized into two categories, that is, to meet their production and operation need and meet its capital structure adjustment needs [5] [6]. Wang Huiyun (2003) pointed out that when raising funds, enterprises must take full account of the cost of financing, quantity, risk and capital structure, so as to choose the most reasonable way to raise funds and raise funds [7]. Lili (2014) believes that in the practical application of 
financing channels and ways of financing, enterprises should take account of the actual development of enterprises, and apply reasonable financing combination strategies to promote the sustainable development of enterprises [8]. Tien Cheng Hsui (2015) believed that in the future, the financing of enterprises should be developed in the direction of diversification of financing methods, the expansion of financing channels and the guidance of non-governmental fund-raising [9].

\subsection{New Financing Optimal Order Theory}

Meyers and Maggie Love's study showed that when stock prices were overestimated, corporate managers would use their internal information to issue new shares. Investors will be aware of the problem of information asymmetry. Therefore, when a company announces the issuance of shares, investors will reduce the valuation of existing stocks and new shares, resulting in a decline in stock prices and a decrease in the market value of enterprises. Endogenous financing mainly comes from the natural formation of cash flow within the enterprise, which is equal to net profit and depreciation to reduce dividends. Due to internal financing need not sign a contract with investors, there is no need to pay various fees, few of the limitations, so it is the preferred way of financing, followed by low risk bonds, the cost of the information asymmetry can be ignored, again is a high risk bonds, finally in no circumstances to issue shares. In general, enterprise financing will follow the order of endogenous financing, debt financing and equity financing.

\section{Company Introduction}

Chongqing Taiji Group Limited by Share Ltd (600129) was founded in November 18, 1993. It is a Limited by Share Ltd. formed by restructuring Sichuan Fuling pharmaceutical factory as the main body. The company was listed on the Shanghai Stock Exchange on October 25, 1997, with a registered capital of 252 million 600 thousand yuan and a total assets of about 6,000,000,000 yuan. Have Chongqing TongJunGe and Southwest Pharmaceutical Limited by Share Ltd Limited by Share Ltd., Taiji Group Chongqing Fuling Pharmaceutical Factory Co., Ltd. 39 subsidiary companies. The company is mainly engaged in processing, selling, selling, processing medical packaging products, medical device sales, Chinese herbal medicine planting, commodity packaging, tourism development and so on. This article takes Taiji Group for 2005-2015 years as the research object, and investigates its financing ways and influencing factors.

\section{Case Financing Structure Analysis}

\subsection{Funding Period}

According to the length of time, enterprise financing methods can be divided into long-term financing and short-term financing. Short-term financing is mainly used to solve the short-term financing needs and liquidity needs of investors, investors mainly use it to meet the needs of asset liquidity management. 
Long-term financing is mainly used to solve the financing needs of the expansion of capital. Investors mainly use it to meet the needs of business management. Long-term financing comes mainly from capital markets, including equity funds and long-term debt funding. Short-term financing mainly includes short-term loans and commercial credit. As the corporate equity funds are long-term funds, and debt funds are divided into long-term and short-term two parts, this article mainly through the current liabilities ratio and non-current liabilities ratio two indicators to examine the Taiji Group's debt financing deadline.

A current liability is a debt that needs to be repaid in one year (including one year). A non-current liability refers to a debt of more than one year (without one year). Based on the statistics of the current and future non-current liabilities ratio of TaiChi group for 2005-2015 (Figure 1), it can be seen that although the two ratios fluctuate each year, especially in 2009-2014, the current liabilities ratio will increase by nearly $10 \%$ The current liabilities ratio dropped by $10 \%$. However, it can be clearly seen from the overall trend that the debt financing of Taiji Group is mainly for long-term financing.

In general, the risk of short-term funding is greater than that of long-term funding because the short-term maturities of funds may be near the risk of liquidating on time. The use of long-term debt to support long-term assets can lock in interest expenses and avoid the risk of short-term interest rate changes. In addition, due to the long-term survival and development of enterprises, they need to regularly hold a certain amount of long-term capital to build fixed assets, acquire intangible assets and carry out long-term investments.

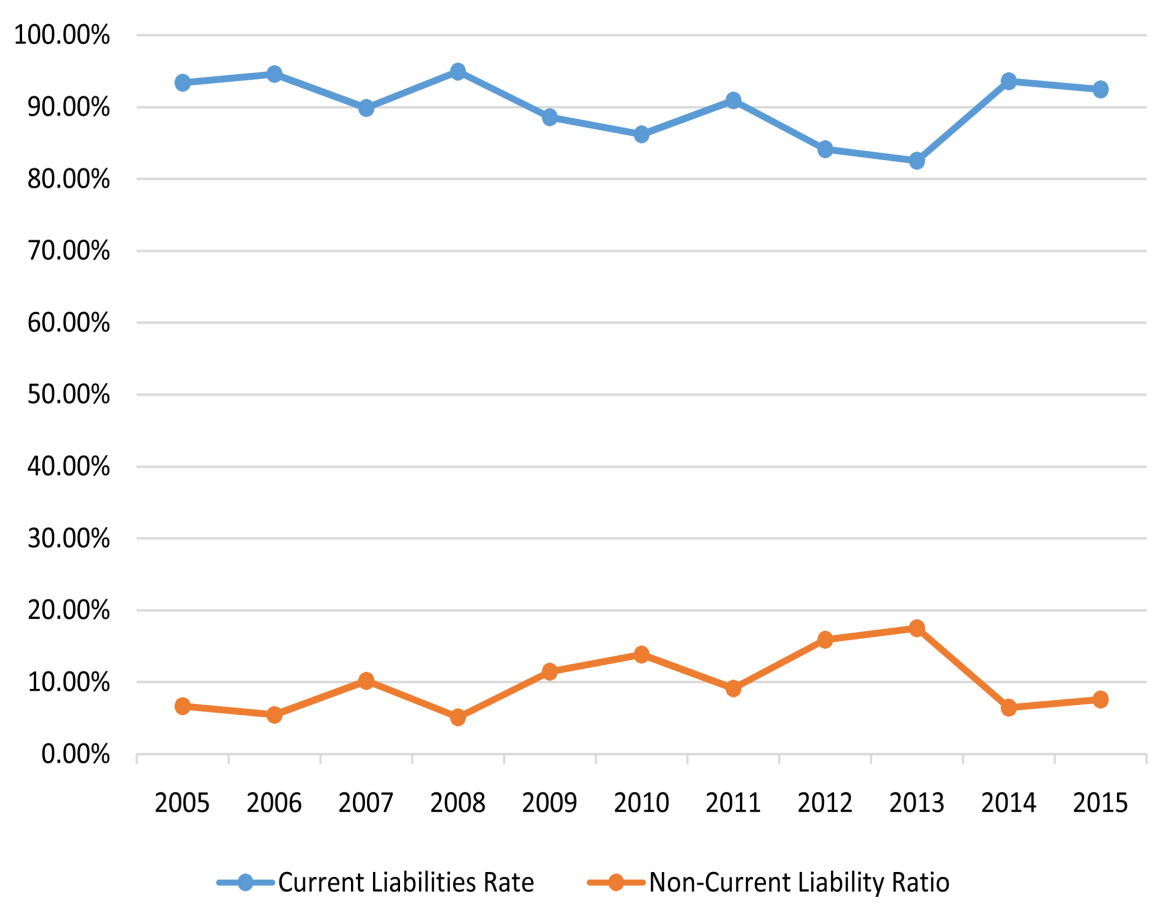

Figure 1. Comparison of current liabilities and non-current liabilities. 


\subsection{Funding Sources}

Long-term financing provides important financial support for the long-term development of enterprises. How to arrange the proportion of long-term financing structure rationally? This article will analyze the Taiji Group in terms of sources of funding, i.e., the ratio of internal financing to external financing, as shown in Table 1 and Table 2.

According to the table, the main source of financing for TaiChi Group is external financing, with an average of about $90 \%$ of external financing each year. The main sources of external financing are debt financing. Comparing the distribution of sources of funding for foreign enterprises shows that the financing of developed countries mainly depends on endogenous financing. In the table,

Table 1. 2005-2015 endogenous financing ratio statistics.

\begin{tabular}{ccccc}
\hline Date & Depreciation of fixed assets & Surplus reserve & Undistributed profit & Total \\
\hline 2005 & $8.71 \%$ & $2.14 \%$ & $2.67 \%$ & $13.51 \%$ \\
2006 & $9.83 \%$ & $2.21 \%$ & $3.21 \%$ & $15.26 \%$ \\
2007 & $10.67 \%$ & $1.27 \%$ & $6.56 \%$ & $18.49 \%$ \\
2008 & $12.12 \%$ & $1.23 \%$ & $6.55 \%$ & $19.90 \%$ \\
2009 & $12.14 \%$ & $1.13 \%$ & $6.56 \%$ & $19.83 \%$ \\
2010 & $11.97 \%$ & $1.05 \%$ & $3.54 \%$ & $16.55 \%$ \\
2011 & $0.02 \%$ & $0.93 \%$ & $1.91 \%$ & $2.86 \%$ \\
2012 & $0.33 \%$ & $0.88 \%$ & $-0.81 \%$ & $0.40 \%$ \\
2013 & $0.49 \%$ & $0.79 \%$ & $-0.59 \%$ & $0.69 \%$ \\
2014 & $8.49 \%$ & $0.99 \%$ & $-4.53 \%$ & $4.95 \%$ \\
2015 & $11.22 \%$ & $1.49 \%$ & $-2.83 \%$ & $9.88 \%$ \\
\hline
\end{tabular}

Table 2. 2005-2015 external financing ratio statistics.

\begin{tabular}{|c|c|c|c|c|c|c|c|c|c|}
\hline \multirow[t]{2}{*}{ Date } & \multicolumn{5}{|c|}{ Debt financing } & \multicolumn{3}{|c|}{ Equity financing } & \multirow[t]{2}{*}{ Total } \\
\hline & $\begin{array}{l}\text { Natural } \\
\text { financing }\end{array}$ & $\begin{array}{c}\text { Short } \\
\text { term loan }\end{array}$ & $\begin{array}{l}\text { Long } \\
\text { term } \\
\text { loan }\end{array}$ & $\begin{array}{c}\text { Bonds } \\
\text { payable }\end{array}$ & $\begin{array}{c}\text { Other } \\
\text { long-term } \\
\text { liabilities }\end{array}$ & $\begin{array}{l}\text { Share } \\
\text { capital }\end{array}$ & $\begin{array}{l}\text { Capital } \\
\text { reserve }\end{array}$ & $\begin{array}{l}\text { Minority } \\
\text { interests }\end{array}$ & \\
\hline 2005 & $33.41 \%$ & $28.42 \%$ & $3.34 \%$ & $0.00 \%$ & $0.00 \%$ & $4.26 \%$ & $10.55 \%$ & $12.82 \%$ & $92.81 \%$ \\
\hline 2006 & $36.70 \%$ & $27.41 \%$ & $2.70 \%$ & $0.00 \%$ & $0.00 \%$ & $4.37 \%$ & $10.94 \%$ & $7.94 \%$ & $90.06 \%$ \\
\hline 2007 & $31.16 \%$ & $29.48 \%$ & $6.01 \%$ & $0.00 \%$ & $0.91 \%$ & $4.36 \%$ & $10.17 \%$ & $8.90 \%$ & $90.99 \%$ \\
\hline 2008 & $33.99 \%$ & $29.05 \%$ & $3.05 \%$ & $0.00 \%$ & $0.64 \%$ & $5.50 \%$ & $6.36 \%$ & $7.44 \%$ & $86.04 \%$ \\
\hline 2009 & $33.62 \%$ & $24.51 \%$ & $7.61 \%$ & $0.00 \%$ & $0.51 \%$ & $5.03 \%$ & $6.96 \%$ & $7.45 \%$ & $85.69 \%$ \\
\hline 2010 & $33.80 \%$ & $26.34 \%$ & $9.44 \%$ & $0.00 \%$ & $0.40 \%$ & $6.07 \%$ & $6.38 \%$ & $7.74 \%$ & $90.17 \%$ \\
\hline 2011 & $36.24 \%$ & $31.59 \%$ & $5.35 \%$ & $0.00 \%$ & $0.20 \%$ & $5.37 \%$ & $5.86 \%$ & $6.32 \%$ & $90.93 \%$ \\
\hline 2012 & $34.76 \%$ & $28.34 \%$ & $3.94 \%$ & $7.67 \%$ & $0.35 \%$ & $5.13 \%$ & $5.62 \%$ & $7.09 \%$ & $92.90 \%$ \\
\hline 2013 & $41.32 \%$ & $25.11 \%$ & $7.42 \%$ & $6.81 \%$ & $0.34 \%$ & $4.56 \%$ & $5.36 \%$ & $5.88 \%$ & $96.80 \%$ \\
\hline 2014 & $44.14 \%$ & $22.29 \%$ & $2.91 \%$ & $0.00 \%$ & $2.32 \%$ & $4.12 \%$ & $9.19 \%$ & $5.66 \%$ & $90.65 \%$ \\
\hline 2015 & $43.65 \%$ & $29.94 \%$ & $0.98 \%$ & $0.00 \%$ & $2.87 \%$ & $4.26 \%$ & $3.19 \%$ & $2.89 \%$ & $87.77 \%$ \\
\hline
\end{tabular}


the lowest internal financing rate was in France, with a financing rate of 42.1, while domestic financing in China was only less than $20 \%$, far below the international average. Dialectically speaking, endogenous financing is the guarantee of exogenous financing. The scale and risk of exogenous financing must be measured by the ability of endogenous financing. If we blindly carry out external financing regardless of the ability of internal financing, it will not only help to increase the utilization rate of resources, but will also make the enterprises fall into the dilemma of expansion and stability. To a certain extent, this set of data reflects the reason why there is a big gap between China's economy and other countries in the world today. Chinese enterprises should increase their ability to source domestic funds and avoid over-reliance on external sources of financing. Financing costs of exogenous financing firms are relatively high and require considerable intermediation fees to be paid to financial institutions, which may result in greater indebtedness for the firm resulting in the company's financial crisis and new crises that occur when the immediate crisis is not resolved leading to some weaknesses in risk-taking Of small and medium-sized enterprises directly closed down. In addition, external financing conditions are also strict. However, most small and medium-sized enterprises are small-scale, their internal management is not standardized, their internal governance structure is imperfect and their core competitiveness lacks. In the industrial division of labor, most SMEs are engaged in processing industries with lower added value, with lower technological content, smaller enterprises, backward equipment technology, non-compliance with environmental protection, low technological content of products, weak market competitiveness, poor credit concept, To achieve the purpose of financing, we must have a lot of relevant qualifications, some SMEs will be blocked in this door (Figure 2, Figure 3).

\subsection{Capital Attributes}

It can be seen from the above analysis that the main sources of funding for the

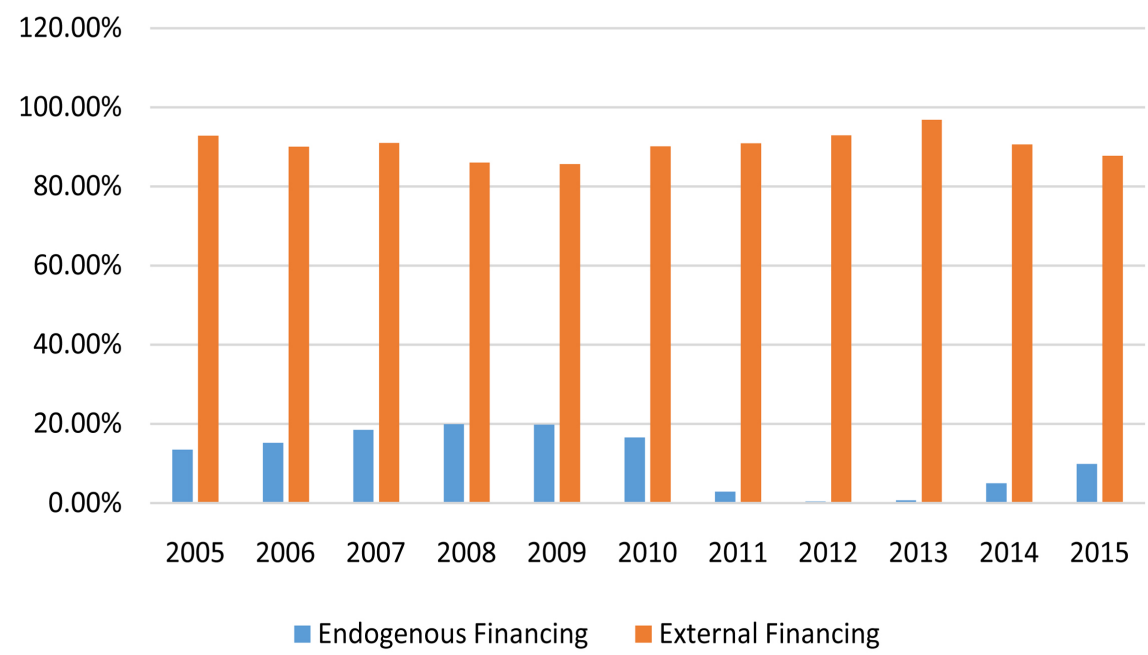

Figure 2. Distribution of sources of funding statistics. 


\begin{tabular}{|c|c|c|}
\hline & Endogenous Financing & External Financing \\
\hline America & 73.7 & 26.3 \\
\hline Britain & 81.1 & 18.96 \\
\hline France & 42.1 & 57.9 \\
\hline Japan & 59.1 & 40.9 \\
\hline
\end{tabular}

Figure 3. Distribution of sources of funding for foreign enterprises.

Taiji Group are external sources of funding, while the external sources of funding are divided into equity funds and debt financing. In the following Table 3, this article will calculate the asset-liability ratio of Taiji Group while referring to the above data.

According to the analysis of the data, the asset-liability ratio of Taiji Group is consistently high and its debt-to-asset ratio is high. This shows that the sources of funds in enterprises are more from debt and less from the owners. Asset-liability ratio is high, the financial risk is relatively high, the cash flow may lead to inadequate, the financial chain rupture, cannot be timely debt service, resulting in corporate bankruptcy. High debt ratio will lead to further financing costs. Both banks and investors have certain requirements on the asset-liability ratio. However, a certain rate of assets and liabilities allows enterprises to use debt leverage to raise corporate shareholders' returns when the interest rate falls below the investment rate of return.

\section{Case Conclusion}

According to the new financing theory, corporate financing generally follows the order of internal financing, debt financing and equity financing. However, through the analysis of the fund-raising methods of Taiji Group, it is found that the main financing method is external financing, which is inconsistent with the new financing theory and compared with the foreign enterprises. It also shows that the internal financing rate of Taiji Group is far below the international average. In terms of funding attributes, TaiChi Group has higher debt financing and lower equity funding, indicating that its fundraising structure is also reasonable.

\section{Analysis of Influencing Factors}

There are many factors that influence the choice of financing methods. There are mainly five aspects, namely, capital requirements, enterprises themselves, financing risks, financing costs and capital structure.

\subsection{Funding Requirements}

The funding requirements of enterprises are the basic influencing factors of financing channels and means of financing. Among them, the three factors of financing amount, time of fund-raising and the period of fund use basically determine the direction of enterprise's financing choice. 
Table 3. 2005-2015 gearing ratio.

\begin{tabular}{cc}
\hline Date & Assets and liabilities \\
\hline 2005 & 0.675783 \\
2006 & 0.713404 \\
2007 & 0.687515 \\
2008 & 0.729145 \\
2009 & 0.728727 \\
2010 & 0.752093 \\
2011 & 0.796061 \\
2012 & 0.820908 \\
2013 & 0.839991 \\
2014 & 0.845494 \\
2015 & 0.869648 \\
\hline
\end{tabular}

\subsubsection{Funding Amount}

The amount of funding is the amount of money the business needs to raise. The amount of fund-raising should correspond to the actual demand of the enterprise. According to the actual demand of the enterprise, the amount of fund-raising of the enterprise should be determined properly. If the amount of the fund-raising is inconsistent with that of the enterprise, too much or too little will result in the loss of the enterprise. Large demand for funds Corresponding issue of stock, bond issuance, direct investment absorption, apply for large loans, etc.; small demand for the use of commercial credit, loans, financing leases.

\subsubsection{Financing Time}

Enterprise financing has a certain timeliness requirements. This requires businesses to be able to raise the funds they need quickly when they are in dire need of money; to make timely reimbursements when not needed, without incurring additional costs due to idle funds or default. Capitalization of the use of timeliness: 1$)$ the use of retained earnings of enterprises; 2 ) the use of commercial credit; 3) bank loans; 4) financial leasing; 5) absorption of direct investment; 6) bond issuance; 7) issue of shares.

\subsubsection{The Period of Use}

Due to the different duration of enterprise development projects, the funds raised by enterprises also have their own useful life. Short-term use of funds, companies need to raise short-term funds; use of a longer period, companies need to raise long-term funds.

\subsection{Business Itself}

The main financing of enterprises is the enterprise itself, the financing target is the strategic goals or development projects. Therefore, the impact of the enterprise's own situation on the financing of enterprises cannot be ignored. 


\subsubsection{The Size of the Enterprise}

In general, the larger the size of an enterprise, the more channels and sources of funding to choose from, and the greater the size of the enterprises, the greater impact the national tax policies have on them. In many countries, many tax incentives for SMEs are often given to promote the development of SMEs. For example, in our country, since January 1, 2008, qualified small profit-making enterprises will be levied a reduction of enterprise income tax at the rate of $20 \%$.

\subsubsection{Business Development Goals}

Motivation for corporate finance comes from the development goals of enterprises. The development goals of enterprises are different and the requirements for fund-raising are different. For example, a company whose development goals are short-term goals will be more likely to raise short-term funds.

\subsubsection{Corporate Credit Status}

Banks or other financial institutions will conduct a credit rating of enterprises to determine the duration of loans and other enterprises, corporate credit conditions even more greatly affected the debt financing of enterprises. The creditworthiness of enterprises is good debt financing easier and less costly.

\subsubsection{Corporate Solvency}

The solvency of an enterprise refers to the ability of an enterprise to pay its debts. It is an important indicator of the financial status of an enterprise. When the solvency of an enterprise is high, the solvency of an enterprise will be more likely to be chosen for debt financing.

\subsubsection{Corporate Profitability}

The profitability of an enterprise refers to the ability of the enterprise to increase the value of its capital. The realization of profitability is the driving force for the enterprise to obtain the maximum capital and the capital movement. The better the profitability of an enterprise is, the faster its development will be. The more the enterprise needs to raise funds. Its risk tolerance is also stronger, more options for debt financing, the available internal funds are more; and poor business development, poor profitability, debt financing should be relatively reduced, to avoid financial risk.

\subsection{Financing Risk}

Business raising money needs to withstand the risks posed by financing. Choosing different ways of raising funds and raising funds will expose them to different financing risks. Funding risks of enterprises mainly include operating risks and financial risks. Enterprises in the choice of means of financing should be comprehensive consideration of the size of the risk of various means of financing. The less risk the more beneficial to the business, in general, the risk of equity financing is less than the risk of bond financing. The risk of issuing shares is less than the risk of issuing bonds. 


\subsection{Financing Costs}

Financing costs are an important factor affecting the choice of financing channels and means of financing. To spare no effort to find the lowest financing cost financing program is the ultimate goal of corporate finance. Financing costs include not only the costs incurred by enterprises to raise funds, but also the financing costs and whether the tax is deductible to reduce the corporate income tax payable. Only companies whose capital returns exceed their funding costs will benefit businesses.

\subsubsection{Cost of Capital}

The cost of capital raised by enterprises mainly comes from external sources of financing, that is, the interest paid by enterprises for borrowing funds. Financial institutions in their own factors to consider or the provisions of national policies, different companies lending interest is not the same, companies should be based on their own conditions and advantages, comprehensive analysis of various factors, to choose the best financing channels (That is, the lowest cost of funds).

\subsubsection{Funding Costs}

Financing expenses, that is, the expenses incurred by the enterprise for raising funds, such as the issuing expenses of stocks or bonds, interest generated from issuing bonds, rent, dividend bonus and so on.

\subsubsection{Deduction before Tax}

Pre-tax deduction refers to the enterprise can deduct items before income tax. For example, interest on borrowings and interest on bonds can be deducted or amortized before tax costs can be deducted, thus playing the role of credit deduction, thus reducing the expenditure of enterprises.

\subsection{Capital Structure}

The capital structure is the core issue in the choice of financing channels and means of financing. The capital structure of an enterprise is related to the survival and development of the enterprise. The capital structure is essentially the ratio of corporate capital to debt. Changes in capital structure may affect the interests of business stakeholders, so companies need to weigh the appropriateness of the ratio of capital to liabilities in order to determine an optimal capital structure, making the enterprise lower overall cost to ensure that the value of the enterprise achieve.

\subsubsection{A Large Proportion of Debt Capital}

Enterprises in the period of development or stabilization have stable incomes and profits, and the capital structure of enterprises naturally prefers to the debt capital, or the capital debt ratio of enterprises is relatively large. Because the debt cost can be deducted before tax, which is smaller than the equity capital, the proportion of the stable and highly competitive corporate debt capital is rela- 
tively large.

\subsubsection{A Small Proportion of Debt Capital}

Enterprises in the new period or early stage of development fluctuate greatly in income and profitability and the solvency of enterprises is relatively weak. Therefore, the capital structure of enterprises naturally tends to equity capital, or the capital debt ratio of enterprises is relatively small. Enterprises choose a small capital structure of debt capital, the maneuver more room to avoid excessive repayment pressure and risk.

\section{Countermeasures for Enterprises to Choose the Way of Raising Funds}

There are some common ways to find out the financing structure for many ways and when enterprises are conducting fund-raising analysis according to their own specific conditions.

\subsection{Looking for the Lowest Funding Costs}

Enterprises in the choice of ways to raise funds, we must first consider the various costs, choose from the internal perspective of the company to measure the minimum cost. This cost includes the financial cost, opportunity cost, risk cost and agency cost mentioned before. This is a factor that enterprises should focus on when choosing ways to raise funds. It is also a decisive factor in the choice of financing, which is more commonly used in the conventional sense.

\subsection{Choose the Most Conducive to Corporate Financial Leverage}

This is from the perspective of risk and profit analysis of financing options, companies should be in the early stages of financing their own future business to make a trade-off, considering the maturity of the fund will bring business risks or benefits, as well as the value of the owner influence level.

\subsection{To Find the Best Capital Structure}

In fund-raising, it is necessary to maximize the share of debt capital in total capital so as to fully obtain the financial leverage while avoiding the financial risks brought by the excessively large proportion of debt capital. Therefore, in the type of financing decisions, financial managers should seek a reasonable balance between financial leverage and financial risk. As a result, the connotation of the optimal capital structure highlights itself.

\subsection{Choose the Most Conducive to Raise the Competitiveness of Enterprises to Raise Funds}

Funding will bring the following impacts to the enterprises: Firstly, through fund-raising, the strength of the enterprises can be strengthened and the ability of enterprises to pay and the development potential can be enhanced so as to 
reduce their competitors; secondly, through the fund-raising, enterprises have increased their scale and profitability, economic advantages, so as to enhance competitiveness and accelerate the development of enterprises; finally, through financing, improve corporate reputation and expand market share of enterprise products, integrity and entrepreneurship. However, the way in which enterprises raise funds and the different returns have great differences in the degree of their competitiveness. Such as stock investment, usually the initial public offering of ordinary shares and traded, will not only bring huge financial facilities to enterprises, but also greatly enhance the visibility and goodwill of enterprises so that the competitiveness of enterprises has been greatly improved. Therefore, when making fund-raising decisions, enterprises should choose ways of raising funds that will enhance their competitiveness.

\subsection{To Develop the Best Financing Deadline Decision}

Divided by period, enterprise financing can be divided into short-term financing and long-term financing. Enterprises make financing period decision-making, mainly depends on the purpose of financing and fundraising risk preferences. From the point of view of fund use, if financing is used for current assets of enterprises, various short-term financing methods are suitable for selection according to characteristics such as fast circulation, easy realization of liquid assets, small supplementary amount required for operation and short occupation time, Short-term loans, commercial credit and more.

\subsection{The Best Choice for Business Opportunities for Financing}

1) The external environment, the enterprise itself has limited impact on the overall financing environment, because the financing opportunity is an objective environment that emerges at a specific time. In most cases, the enterprise can only adapt to the external financing environment without affecting the external environment. Therefore, enterprises must give full play to their initiative, actively seek and timely grasp various favorable opportunities to ensure the success of fund-raising.

2) Enterprise financing must be forward-looking and the external financing environment of the enterprise is complex and changeable. The domestic and international interest rates, exchange rates and other financial markets should be grasped with various information in a timely manner so as to understand the macro-economic situation at home and abroad, the national monetary and fiscal policies As well as the political environment and other external factors, a reasonable analysis and prediction of various favorable and unfavorable conditions that can affect the financing of enterprises in order to find the best time for funding and make decisive decisions

3) We must work in line with the actual situation of the enterprise, give full consideration to the specific characteristics of the fund-raising methods, and formulate a timely and appropriate decision to raise funds. 


\section{References}

[1] Ross, S. (1972) Determinants of Corporate Borrowing. Journal of Financial Economics, No. 5, 147-175.

[2] Smith, C.W. and Watts, R.L. (1992) The Investment Opportunity Set and Corporate financing, Dividends, and Compensation Policies. Journal of Financial Economics, 32, 263-292. https://doi.org/10.1016/0304-405X(92)90029-W

[3] Simon, M. (2002) On the Existence of an Optimal Capital Structure: Theory and Evidence. Journal of Finance, No. 39, 857-880.

[4] Zhao, R. (2015) Analysis of Problems and Countermeasures in the Financing of Small and Medium Enterprises in China. China Management Information, 18, 33.

[5] Zhou, L.L. (2015) Difficulties in Raising Funds for Small and Medium-Sized Enterprises and Solutions to Countermeasures. Economic Research Guide Journal, 21, Article ID: 99100.

[6] Gao, X.L. and Qiao, R.Z. (2015) Research on the Financing Ways and Countermeasures of Small and Medium Enterprises in China. New Economy, 4, 6162.

[7] Trade Union Cloud (2003) Talk about Enterprise Fund-Raising Channels and Fund-Raising Ways. Modern Management Science, No. 6, 55-56.

[8] Li, L. (2014) The Combination Strategy of Enterprise Financing Channels and Financing Methods. ERA Finance, No. 4, 111.

[9] Xu, T.C. (2015) The Choice of Financing Channels and Financing Methods of Chinese Enterprises. Cooperation Economy and Science and Technology, No. 2, 76-77. 